6. некоторое родство нуристанского и дардского - с наиболее близким к ним иранским языком - пушту охватывает в основном фонетику и лексику, что связано с историей и спецификой генезиса пушту;

7. нуристанские и дардские языки выборочно можно использовать для исследования генезиса осетинского языка.

$$
* * *
$$

1. Языки Азии и Африки. Индоевропейские языки: иранские языки, дардские языки. Дравидийские языки. II. М., 1978. 440 с.

2. Гордон Чайли. Арийцы. Основатели европейской цивилизации. М., «Центрполиграф», 2007г. $207 \mathrm{c}$.

3. Основы иранского языкознания. Новоиранские языки: восточная группа. Москва, «Наука», 1987. $720 \mathrm{c}$.

4. Камболов Т.Т. Очерк истории осетинского языка. Владикавказ, «Ир», 2006г. 463с.

5. Оранский И.М. Введение в иранскую филологию. М., 1988г. 392c.

6. Грюнберг А.Л. Языки Восточного Гиндукуша. Язык Кати. М., «Наука», 1980г. $296 \mathrm{c}$.

7. Религии Гиндукуша. М., «Наука», 1986г. 524c.

8. Сатцаев Э.Б. Осетинский и афганский языки: сравнительно- сопоставительный анализ. Владикавказ, 2013г. 134c.

9. Эдельман Д.И. Сравнительная грамматика восточноиранских языков: фонология. М., 1986г. 232c. 10. Кузьмина Е.Е. Арии - путь на юг. М.: Летний сад, 2008г. 558c.

11. Абаев В.И. Историко-этимологический словарь осетинского языка. Указатель. Составители: Сченснович Е.Н., Лушникова А.В., Додыхудоева Л.Р., М., 1995г. 448 с.

\title{
Седых Н.Д.
}

Анализ фразеологизмов английского языка с компонентом цветообозначения

Белгородский государственный наџиональный исследовательский университет НИУ «БелГУ》

doi: $10.18411 / 1 j-11-2019-245$

(Россия, Белгород)

idsp: ljournal-11-2019-245

Аннотация

В статье рассмотрено понятие фразеологизма, проанализированы фразеологические единицы с компонентом цветообозначения, их значение, эмоциональная окрашенность.

Ключевые слова: фразеология, фразеологическая единица, компонент, цвет, цветообозначение.

\section{Abstract}

This paper deals with the notion of the phraseological unit, analyzes phraseological units containing color, their meaning, emotional coloring.

Keywords: phraseology, phraseological unit, component, colour, colouring.

Фразеология (от греч. phrasis, «выражение» и logos «учение») - это раздел науки о языке, изучающий фразеологическую систему языка в ее современном состоянии и историческом развитии. Объектом изучения фразеологии являются фразеологические единицы, т. е. устойчивые сочетания слов, воспроизводимые в речи в готовом виде и целостные по значению.

Фразеологическая единица - «этнически, культурно обусловленное сложное структурно-смысловое ... образование, ... включающее в себя, помимо понятия, образ, оценку, культурную ценность и функционально замещающее человеку ... однопорядковые предметы, вызывающие пристрастное отношение к ним человека» [7]. 
Значение фразеологизма определяется не отдельными, входящими в него словами, а складывается из всех значений слов, его составляющих. Компоненты фразеологизма обычно нельзя поменять местами, заменить на другие. И только в целом фразеологическая единица имеет свой смысл.

Современный английский язык наполнен разнообразными фразеологизмами и речевыми оборотами. Значительную часть этих оборотов занимают фразеологизмы с компонентом цветообозначения. Данные фразеологические единицы несут не только свое прямое значение, но и также передают дополнительную информацию с помощью использования цвета.

Определенный цвет формирует определенные чувства: радость и злость, волнение, спокойствие, безразличие, ощущение холода или тепла. То есть каждый цвет имеет свое уникальное значение. Один английский фразеологизм отлично передает значение и роль цвета в нашей жизни: "to see someone in their true colours" - предстать в истинном свете, сбросить маску.

Каждая культура имеет свой особый набор наиболее распространенных цветов. В европейской культуре основными цветами являются белый, черный, красный, синий, зеленый, желтый и фиолетовый [6].

Таким образом, изучая фразеологизмы языка, можно получить наиболее полное представление о носителях этого языка, ведь именно во фразеологизмах отражается история народа, быт и мировоззрение.

Мы провели детальный анализ и описание фразеологических единиц с компонентом цветового обозначения на основе одного из авторитетных англо-русских фразеологических словарей (Collins COBUILD Dictionary of Idioms). Методом сплошной выборки мы отобрали 65 фразеологических единиц английского языка, содержащих компонент-цвет, и составили характеристику значений выражений с каждым цветом.

Белый цвет в большинстве случаев несет положительную коннотацию. Он символизирует счастье, красоту, чистоту, доблесть, непорочность, честность: “a white lie" - ложь во спасение; "whiter than white" - кристально чистый.

Нижеприведенные фразы свидетельствуют о том, что фразеологизмы с цветовым компонентом встречаются в современной англоязычной литературе: "The woman's hair was white as snow, her skin was wrinkled, and one eye was blind." (Волосы женщины были белее снега, морщинистая кожа свисала складками, а вместо одного глаза блестело бельмо) [1]; She was as white as the sheet and notwithstanding his tan his cheeks were pale tоо. (Она была белее простыни, и сам он побледнел под загаром) [4].

Белый - цвет спокойствия и мира: "to show the white flag" - сдаваться; показывать добрые намерения. Это цвет великодушия, достоинства, благородства. Об этом свидетельствуют символы государственности, включающие в себя этот цвет: “Тhе White House" - правительство США и его резиденция.

Отрицательное значение белого также существует. Это болезнь, испуг, беспокойство, одиночество. К примеру, “white as a ghost” - бледный как смерть; бледный как полотно.

Голубой (синий) цвет ассоциируется с властью и высоким положением: ”blue blood" - королевская семья или люди благородного происхождения. Голубой цвет обозначает верность, постоянство, строгость: “blue to principles" - верный принципам.

В следующих выражениях голубой имеет значение чего-то неожиданного, странного, неопределенного: “out of the blue" - совершенно неожиданно; как снег на голову; "once in a blue moon” - в кои-то веки; по большим праздникам; "out of a clear blue sky” - ни с того ни с сего.

Одновременно это цвет грусти и неуверенности: “blue devils” - уныние; "to cry the blues" - прибедняться, "to be in the blues" - сбиваться с пути; терпеть неудачу; "a bolt from the blue" - неожиданная неприятность; "It fair turned my ears blue, it did." (Eü- 
богу, у меня уши в трубочку сворачивались) [1]; "I would be black and blue all over for days at a time." (В такие дни я ходила вся в синяках и кровоподтеках) [3]; "I've been thinking of the past and I'm as blue as the devil." (Я думала о прошлом, и у меня теперь страшная хандра) [2].

В найденных выражениях красный цвет чаще всего означает войну, кровь, пламя, опасность: "to catch someone red-handed" - поймать с поличным; “a red flag" предупреждение об опасности. Красный цвет так же ассоциировался с чувством злости: "red as a beet(root)" - красный до корней волос; "a red rag to a bull" - красная тряпка для быка; "to see red" - прийти в ярость; "He never let red tape interfere with him." (Презирает волокиту) [4]; “And how, then, will you recognise merit?” asked Dirk, red in the face with anger." (А как вы в таком случае определяете, кто его достоин? - спросил Дирк, красный от гнева) [3].

Следующие фразеологизмы, вероятно, появились из-за обыкновения записывать долги и кредиты красным цветом: "to bleed red ink" - испытывать серьезные денежные затруднения; "to be in the red" - иметь долги; "not a red cent" - ни копейки.

Черный цвет всегда скрывает в себе то, что несет, то есть он загадочен, неясен: "a black box" - «черный ящик», что-то непостижимое. Этот цвет имеет такие значения как «секретный», «злой», «нелегальный»: “black money” - грязные деньги; “blackmail” - шантаж; "a black look" - недобрый, угрюмый, не предвещающий ничего хорошего взгляд; "I may not have to leave the service, but there always be a black mark against me." (Со службы меня, возможно, и не выгонят, но и продвинуться не дадут репутация-то подмочена) [4].

Зеленый цвет приносит спокойствие и умиротворенность, помогает в концентрации и принятии решений: "give the green light" - давать зеленый свет; одобрять (план, проект); "the grass is always greener on the other side of the fence" - на соседней лужайке всегда трава зеленее; "greener pastures" -лучшие условия.

Прилагательное "green" считается символом молодости, неопытности, а так же зависти: "as green as grass" - молодой, неопытный, «зеленый»; "green-eyed" ревнивый; "green with envy” - позеленевший от зависти. В негативном аспекте это цвет безнадежности. Также данный цвет может вызывать скуку, передавать значение болезни: "green around the gills" - выглядеть больным.

В найденных фразеологизмах зеленый цвет также появляется при обозначении природы, садоводства: "have a green thumb" - иметь успех в садоводстве; "have green fingers" - уметь выращивать растения, иметь талант садовода.

Приведем пример использования фразеологизма с компонентом цветообозначения в художественной литературе: "I know that you're not terribly rich and I knew you'd spent a lot on green fees." (Я знаю, что ты не так уж богат и потратил кучу денег на чаевые, когда играл в гольф) [2].

Цвет "grey" ассоциируется с возрастом, мудростью и благородством: "grey hairs" - старость; "to turn grey” - поседеть; "the men in grey suits” - начальство, власти. Также серый ассоциируется с чем-то неясным, странным, подозрительным: “a grey area” - дело темное [8].

При анализе выбранных единиц мы определили, какой компонент цвета в английских фразеологизмах встречается чаще. Это красный $(22 \%)$, голубой $(20 \%)$ и черный $(17 \%)$.

Нам удалось выявить не только типичные значения для каждого цвета, но и его эмоциональную окрашенность. Проанализировав все отобранные выражения, мы подсчитали количество фразеологических единиц с положительным, нейтральным и отрицательным значением. Выяснилось, что большая часть фразеологизмов имеет отрицательное значение, а количество положительных и нейтральных значений одинаково. 
Рассмотрев отдельно данные по каждому цвету, мы заметили, что отрицательное значение преобладает среди фразеологизмов с черным и красным цветовыми компонентами. Сравнив полученную информацию с переводом фразеологических единиц, мы удостоверились, что часто передают отрицательное значение именно выражения, имеющие в составе слова "black" или "red". Также было выявлено, что зеленый цвет в большинстве случаев имеет положительное значение. Он приносит спокойствие и умиротворенность, обозначает природу, является символом молодости.

В ходе выполнения данной работы было установлено, что фразеологические единицы с компонентом цветообозначения несут в себе не только свое прямое значение, но и также передают дополнительную информацию с помощью цвета.

Фразеология является носителем богатейшей информации о представителях английской культуры, о культурно-этническом колорите, поскольку именно во фразеологизмах отражается история народа, быт и мировоззрение.

$$
* * *
$$

1. Gaiman N. Stardust. - William Morrow, 2016. - 272 c.

2. Maugham W.S. Theatre. - Random House, 2016. - 242 c.

3. Maugham W.S. The Moon and Sixpence. - Kapo, 2013. - 384 c.

4. Maugham W.S. The Painted Veil. - Kapo, 2014. - 256 c.

5. Англо-русский словарь устойчивых словосочетаний = Collins COBUILD Dictionary of Idioms. M.: ООО «Издательство АСТ»: ООО «Издательство Астрель», 2004. - 752 с.

6. Базыма Б.А. Цвет и психика. Монография. - Х.: ХГАК, 2001. - 172 с.

7. Красавский Н.А. Образы эмоций в русской языковой картине мира // Русский язык в школе. 2002. - № 2. - 90-94 c.

8. Люшер М. Магия цвета / М. Люшер. - Харьков, 1996. - 432 с.

\section{Седых Н.Д. \\ Особенности перевода фразеологизмов в произведениях современной англоязычной литературы}

Белгородский государственный нациинальный исследовательский университет НИУ «БелГУ》

doi: $10.18411 / \mathrm{lj}-11-2019-246$

(Россия, Белгород)

idsp: ljournal-11-2019-246

\section{Аннотация}

В статье рассмотрено понятие фразеологизма, его основные признаки, способы и приёмы перевода фразеологизмов с исходного языка на язык перевода. Подчёркнуто значение личности переводчика при выполнении перевода.

Ключевые слова: фразеология, фразеологическая единица, фразеологический перевод, нефразеологический перевод, исходный язык, язык перевода, переводчик

\section{Abstract}

This paper deals with the notion of the phraseological unit, the main means and ways of the translation of phraseological units from the source language to the target language. The significance of the translator's personality is emphasized.

Keywords: phraseology, phraseological unit, phraseological translation, nonphraseological translation, source language, target language, translator.

Фразеология (от греч. phrasis, «выражение» и logos «учение») - это раздел науки о языке, изучающий фразеологическую систему языка в ее современном состоянии и историческом развитии. Объектом изучения фразеологии являются фразеологические 